\author{
Alann J. Scott \\ University of Califórnia \\ scottaj@ucla.edu
}

\title{
Resumo
}

Os setores econômicos que lideram o capitalismo contemporâneo, suas tecnologias, suas relações de trabalho e a estrutura de seus mercados, caracterizam as dimensões da atual economia cognitiva cultural. Esta economia marca a sua presença, particularmente, nas grandes regiões-cidade. Inovação contínua na produção, o que significa alta capacidade criativa é um aspecto desta economia que deu margem a conceitos como indústrias criativas e cidades criativas. A noção de uma economia cognitiva cultural introduz o fato de que os processos de trabalho passam a depender cada vez mais de ativos intelectuais e afetivos humanos. Embora tal processo esteja apagando a antiga clássica separação fordista de setores, por colarinhos brancos e colarinhos azuis, no entanto o novo quadro continua apresentando as fortes desigualdades entre um andar de cima e um andar de baixo da classe trabalhadora. E que rebate sobre as estruturas urbanas.

Nem a instalação de setores de população de alto nível cognitivo cultural substitui, como querem alguns, o conceito de classe fundado na relação capital/trabalho e de seus interesses frente à apropriação do excedente; nem o simples aumento de atividades cognitivo culturais numa cidade garante um processo de causação circular de desenvolvimento econômico. $\mathrm{O}$ motor do crescimento continua sendo o aparato complexo de produção, uma rede de atividades industriais e de serviços interrelacionadas e articuladas a mercados finais os mais numeroso. Quanto á desigualdade social, que tem acentuado fragmentações sociais e urbanas é urgente o re-engajamento por princípios de equidade, no contexto de uma consciência de social democracia e de gestão participativa. Não apenas porque são justos em si mesmos, mas, também, porque alargam a esfera da criatividades, aprendizagem, inovação, experimentação social e expressão cultural.

Palavras chave: sistema cognitivo cultural, indústrias criativas, cidade criativa, sociedade pós-industrial.

\begin{abstract}
The cognitive-cultural dimensions of contemporary are identified by reference to its leading sectors, basic technologies, labor relations systems and market structures. Cognitive-cultural systems of production and work come to ground preeminently in large city regions. The expansion of sectors that thrive on innovation is one of the features of the new economy that introduces concepts as creative industries and creative cities. The notion of a cognitive-cultural economy refers above all to the circumstance that labor have come do depend on intellectual and affective human assets. While the old white color/blue color principle of classical Fordism was deeply modified by the new economy, the new labor force is still divided in two tiers, with large wage and cultural inequalities between the upper and the lower parts of the working class. These differences reflect on the fragmented urban structures.
\end{abstract}


Neither the proposition of a creative class, made by some authors can replace the classical concept of class based on interests clash between capital and work in claims on the economic surplus. Nor a simple increase of a creative population in a city will guarantee a continuous growth. The primary engine of this process is a complex apparatus of production, a network or interrelated industrial and service activities and tied to widening final markets. For transcendence of social and urban fragmentation and inequality it is urgent a re-engagement for equity principles, for participatory democracy and for a conscientious program of social democracy. Not just because they are important in their own right - but also because they enlarge the sphere of creativity, learning, innovation, social experimentation and cultural expression.

Key words: cognitive cultural system, creative industries, creative cities, post-industrial society.

Introdução

As dimensões cognitivas culturais do capitalismo contemporâneo são identificadas através de referências aos seus setores de liderança, às suas tecnologias básicas, a seus sistemas de relações de trabalho e às suas estruturas de mercado. Os sistemas cognitivos culturais de produção e trabalho aparecem de forma preeminente nas grandes regiõescidade. Este estado de coisas se manifesta em diversos clusters de setores de alta tecnologia, de funções de serviços, de atividades de manufatura neo-artesanal e de indústrias de produtos culturais, que são comumente encontradas nestas regiões. Ele também se manifesta pela formação de um largo estrato de empregados de alta qualificação cognitiva cultural em áreas urbanas. Muitos destes empregados se encontram engajados em formas distintas de aprendizagens baseadas no trabalho, de criatividade, e de inovação. Ao mesmo tempo, a economia cognitiva cultural nas cidades contemporâneas é, invariavelmente, complementada por grande número de trabalhos de baixo salário e baixa qualificação, as pessoas imersas nestes trabalhos sendo compostas, comumente, de imigrantes de países em desenvolvimento. As ramificações ideológicas e políticas desta situação estão sujeitas a análise num contexto da crítica de uma idéia atualmente na moda, a da “cidade criativa”.

Adianto o reclamo de que devemos ir além de prescrevem a instalação de pacotes de amenidades selecionadas, como um meio de atrair trabalhadores de elite para determinadas áreas urbanas, quando advogamos pelo desenvolvimento de economias locais. Em vez disso, proponho que os tomadores de decisão devem prestar atenção maior às dinâmicas do sistema de produções cognitivas culturais como tal. No interesse de modelar comunidades urbanas viáveis no capitalismo contemporâneo, devemos ser 
mais resolutos em tentativas de reconstruir sociabilidade, solidariedade e participação democrática.

\section{Capitalismo e Urbanização}

Onde quer que o capitalismo realize a sua aparição histórica e geográfica, seguem-se, invariavelmente, padrões peculiares e níveis crescentes de urbanização. Esta condição resulta de pressões nos sistemas econômicos capitalistas que conduzem de forma persistente à formação de paisagens de grandes agregações de capital físico e de trabalho humano. Por um lado, grupos seletos de firmas a procura do lucro, principalmente, quando enredadas em diversas interdependências funcionais, apresentam uma tendência definida de se localizar próximo a seu cento de gravidade. Por outro lado, é típico observar massas de trabalhadores individuais serem atraídos por centros onde nos quais as oportunidades de trabalho são largamente disponíveis. A trajetória de desenvolvimento de qualquer nó urbano pode ser descrito, portanto, em termos de uma espiral de interdependências, na qual capital e trabalho exercem continuadamente uma força atrativa, uma na outra, em círculos seguidos de causação cumulativa. Um movimento intensificado pela emergência de economias externas de escala e alcance (SCOTT, 2000). Estes processos são certamente dependentes intimamente dos mercados finais e sujeitos a reversão, quando - entre outras razões, os mercados colapsam.

Como o capitalismo assume diferentes formas e conteúdos substantivos em tempos e lugares diferentes, os centros urbanos por ele alimentados refletem séries correspondentes de resultados substantivos específicos. O século 19, na Grã Bretanha, assistiu ao crescimento das clássicas cidades industriais, com as suas empobrecidas populações da classe trabalhadora. No século 20, na América do Norte, as grandes metrópoles industriais floresceram na base do sistema de produção de massa fordista. $\mathrm{O}$ momento presente da história é um no qual o assim chamado capitalismo pós-fordista (ou melhor, dizendo, cognitivo cultural) entrou em cena, em diversas partes do globo. Junto com ele, apareceu um novo padrão urbano, um que apresenta um crescente distanciamento entre a camada superior e a camada inferior da força de trabalho. Muito da atividade produtiva de hoje envolve tecnologias digitais e organização flexível que 
sustentam a expansão de setores que prosperam de inovações, da diversidade de produtos e da provisão de serviços personalizados.

A noção de uma economia cognitiva cultural refere, antes de tudo, à circunstância de que os processos de trabalho passam a depender, cada vez mais, e mais, de ativos intelectuais e afetivos humanos (em ambos os níveis, o de alta e o de baixa remuneração) e são crescentemente menos focal.

Devo argumentar que no contexto destes desenvolvimentos, é possível agora apontar para certos detalhes dos aspectos da gestação que esteve presente nas últimas duas décadas e que marcam a versão particular da relação capitalismo e urbanização. Uma observação importante é que a atual consolidação da economia cognitiva cultural em muitas grandes cidades parece se propagar em novas rodadas de atividades criativas, e como resposta, não apenas no sistema produtivo, como no ambiente urbano mais amplo. É claro que o sistema capitalista foi sempre caracterizado por uma dimensão cognitiva cultural, que sempre foi a fonte de forças inovativas em cidades (HALL, 1998). No entanto, a substância e a magnitude destas forças exibem uma conexão mediata, típica, em relação às especificidades da ordem sócio econômica. Isto é, elas são mobilizadas e assumem conteúdo tangível em relação a tarefas e oportunidades que quase sempre conduzem uma relação controlada para realidades contemporâneas concretas. Apressome a acrescentar, sabendo que esta última sentença será vista de soslaio em alguns meios, que eu não estou propondo, aqui, a reinstalação de um estruturalismo rígido, mas, que também não quero indulgir nas vacuidades de uma concepção puramente voluntarista da vida social. Diferentes imaginações são possíveis em relação a qualquer substrato social e - aqui se encontra o ponto - que podem ser utilizadas a serviço da ação política direcionada para a mudança social (JESSOP. 2004). Atualmente, um substrato cognitivo cultural bem distinto está abrindo caminho nos países de capitalismo avançado, e em paralelo a este desenvolvimento, uma série específica e penetrante de energias sociais também entra em jogo. Uma das imaginações potentes que apareceu para dar sentido e naturalizar esta situação emergente se encontra articulada no trabalho de Florida (2002 1994). No qual ela se refere como a "classe criativa” e a "cidade criativa”. No presente artigo, proponho um caminho alternativo na aproximação às questões levantadas por Florida. Ele pode ser forjado na base da idéia mais abrangente 
de capitalismo cognitivo cultural e na sua manifestação num padrão único, multifacetado de desenvolvimento urbano.

As Dimensões Cognitivas Culturais de Produção e Trabalho no Capitalismo Contemporâneo.

Qualquer expressão concreta da ordem econômica capitalista pode ser descrita, tipicamente, em primeira instância com referência a 1.) seus setores de liderança, 2.) a seus fundamentos tecnológicos, 3,) suas formas características de relações de trabalho, e 4.) as práticas competitivas que desatrela. (BOYER, 1986) Cada uma destas atividades sistêmicas é manifesta de forma única na versão emergente do capitalismo cognitivo cultural.

Primeiro, muito da economia contemporânea é dirigida por setores chave como a manufatura de tecnologia intensiva, serviços de todas as variedades (negócios, financeira, pessoal), produção artesanal orientada para a moda, e indústrias de produtos culturais (incluindo a mídia). Estes setores não cobrem, sem dúvida, a totalidade da atual produção do sistema capitalista, mas se encontram, certamente, nas pontas que lideram o crescimento e a inovação nos países economicamente avançados. Segundo, e sem se contrapor à evidente heterogeneidade desses setores, elas foram todos profundamente penetrados pelas tecnologias digitais que, em retorno, facilitaram a difusão ampla do abandono de rotinas nos processos de trabalho e o abandono de produtos standartizados. Terceiro, as relações de emprego tem sido submetidas à uma flexibilização e desestabilização radical, consequentemente injetando níveis elevados de precariedade nos mercados de trabalho, para trabalhadores em todos os níveis de qualificação e de formação de capital social. Quarto, tem havido uma marcante intensificação de competição (reforçada pela globalização) em todas as esferas da economia , apesar de muito desta competição ocorrer em formas Chamberlíneas modificadas, uma vez que produtos com altos cocientes de conteúdo cognitivo cultural comumente possuem aspectos de quase mono pólio. $\mathrm{O}$ que os torna substitutos imperfeitos de uns para outros e, consequentemente, suscetíveis a criarem estratégias de marketing para a formação de nichos.

Enquanto estas tendências avançavam, o antigo princípio de estratificação da organização da produção e do mercado do trabalho, o princípio de colarinho Geo UERJ - Ano 12, no. 21, v. 2, p. xx-xx $2^{\circ}$ semestre de 2010. www.geoueri.ueri.br/ojs ISSN 1981-9021 
branco/colarinho azul, tão característico do Fordidmo clássico, também foi profundamente modificado. De um lado, como argumentado por Autor et allii (2003) e por Levy e Murnane (2004), o advento da computarização significou que muitas das funções de rotina estão sendo rapidamente automatizadas. Tanto as rotinas que eram integrais no trabalho da antiga fração de colarinhos brancos, (como em contabilidade, gestão de registros, cálculo, saída de informações, etc.) como as da fração dos colarinhos azuis (primeiramente nas operações manuais repetitivas). De outro lado, esta mesma tendência tem sido associada à formação de uma nova elite (core) da força de trabalho. Cujo trabalho se acha concentrado, primeiramente, em tarefas de solução de problemas de alto nível, e de uma nova fração proletária (periférica), que é crescentemente chamada a funcionar como uma fonte de trabalho flexível, em trabalhos como operar máquinas, (como motoristas), manipular materiais (como empacotar montagens de componentes variados) funções de segurança, limpeza, cuidado de crianças. Estes trabalhos envolvem significados graus de engajamento físico e chamam muito menos em termos de qualificação formal e treinamento, em comparação com os anteriormente mencionados. Mesmo assim, eles estão imbuídos de uma variedade significativa de conteúdo cognitivo cultural.

A camada superior da força de trabalho do sistema de produção cognitivo cultural pode ser identificado, em termos de amplas categorias ocupacionais, em gestores, trabalhadores profissionais, analistas de negócios e financeiros, pesquisadores científicos, técnicos, artesãos qualificados, designers, artistas. Estas são ocupações que requerem níveis significativos de capital humano, e são geralmente bem pagos, embora isto não seja tão invariável (MCROBBIE, 2004). Para começar, trabalhadores de gestão e coadjuvantes exercem a função de administração, monitoramento e controle do sistema de produção como um todo. Segundo, analistas qualificados e outros profissionais são necessários para manter os negócios especializados e as operações financeiras do capitalismo moderno. Terceiro, trabalhadores científicos e técnicos são empregados em grande número para supervisionar a infra-estrutura técnica subjacente da economia cognitivo cultura, assim como, satisfazer a sua sede por altos níveis de inovação. Quarto, muitos dos setores da economia cognitiva cultural são caracterizados por um forte elemento de serviços, requerendo intermediação humana na interface produção-consumo, e chamando por uma manipulação qualificada de capacidades afetivo-comportamentais, no lado do suprimento. Quinto, trabalhadores com 
sensibilidades artísticas e intelectuais bem afiados, assumem uma crescente parte importante da força do trabalho, porque o capitalismo contemporâneo é também o lugar de uma notável florescência de indústrias de produtos culturais, no sentido mais largo (isto é, indústrias com produtos permeados com algum grau de conteúdo estético e semiótico, e onde matérias como moda, sentido, aparência, sentimento, conformam significativamente as escolhas do consumidor).Em cada um destes tipos, doses pesadas do toque humano são requeridas para os propósitos de gestão, pesquisa, reunião de informações e síntese, comunicação , trocas inter-pessoais, design, a infusão de sentimento, conteúdos de sentimento e simbólicos dentro de produtos finais. A força de trabalho de elite que sustenta estas funções se expande rapidamente, especialmente nas áreas metropolitanas maiores.

Ao lado desta camada superior de trabalhadores, existe um terço inferior empregado num espesso estrato de atividades produtivas manuais que não é tão bem pago e muito menos gratificados em sua recompensa psíquica. Refiro-me a ambos, as operações de oficinas e fabris que subjazem a muito da atual economia cognitiva cultural (como em muitos setores de alta tecnologia e neo-artesanais) e a empregos de baixo grau em serviços como de zeladores, vigias, ocupações não qualificadas hoteleiras e de restaurantes.Adiciona-se um significante nicho de emprego informal, sustentado pela demanda de trabalhadores mais bem pagos por trabalho doméstico, para realizar tarefas como limpeza de lares, consertos, jardinagem, cuidar de crianças. Esta parte estendida em baixo do corpo da economia cognitiva cultural é notória por suas operações suarentas e freqüentes entrelaçamentos com a ilegalidade, no que diz respeito às leis trabalhistas. Nos países mais avançados, elevada proporção da força de trabalho deste segmento é feita de imigrantes (muitos deles, indocumentados) de partes em desenvolvimento do mundo. Grande número destes imigrantes forma uma subclasse poliglota, com presença social e política marginal no ambiente anfitrião.

A diferença entre o rendimento médio destes dois estratos da força de trabalho, identificados nos parágrafos prévios vem crescendo, passo a passo, nos Estados Unidos, durante a última década aproximadamente. (AUTOR et allii, 2006, MORRIS e WESTERN, 1999, YUN, 2006). Ambos, também, estão sujeitos a muita instabilidade do mercado de trabalho. Trabalhadores de tos os tipos enfrentam, crescentemente, 
turnos freqüentes de desemprego, e se encontram cada vez mais de serem pegos em modos de trabalho temporário, de tempo parcial, de freelancer.

Junto com estas tendências na estrutura das relações de emprego, viu-se o andamento do que alguns analistas identificam como um sentido declinante de fidelidade de trabalhadores a qualquer empregador (BECK, 2000). Com certeza as capacidades de cada um desses grupos para lidar com esses predicamentos difere dramaticamente. Enquanto que, para ambos os grupos as suas redes sociais se constituem em fonte maior para as informações sobre o mercado de trabalho, os indivíduos do estrato superior, via de regra, dispõem de recursos, em termos de contatos e know how inter-pessoal que lhes permite maior raio de manobra.

Na sociedade contemporânea não é incomum encontrar trabalhadores cognitivos culturais que empreenderam trabalho em rede para algo como uma bela arte. Ou, dito de forma mais acurada talvez, se entregaram a um habito de vida semi-rotineiro, no qual devotam porções consideráveis de tempo para socializar com colegas trabalhadores, trocando informações um com outro a respeito de oportunidades de emprego e o estado do mercado de trabalho. Reputação é um item chave de valor nestas condições fluidas de emprego. É um fator maior, lubrificando o progresso de trabalhadores do estrato superior através do sistema de emprego. Uma estratégia seguida por muitos indivíduos neste estrato consiste na acumulação de porto fólios pessoais de experiências de emprego, demonstrando a profundidade e diversidade das trilhas de suas carreiras e realizações criativas até então (NEFF et allii, 2005).Para estes trabalhadores, também elaborar carreira auto gerenciadas é uma forma de substituir as funções burocratizadas pessoais da corporação tradicional.

\section{A Economia Cognitiva Cultural e a Metrópole}

Enquanto esta nova ordem econômica crescia ao longo do par de décadas passadas, ela encontrou um solo fértil em grandes áreas metropolitanas, como Nova York, Los Angeles, Londres, Paris, Amsterdã e Tóquio (SASSEN, 1994). Esses são os hubs capitânia da nova economia, e os centros nervosos de um sistema de produção cognitiva cultural, crescentemente engrenado com mercados que se estendem pelo globo inteiro. 
Atividades de produção cognitiva cultural se encontram, portanto, tipicamente concentradas em clusters locacionais densos, todavia o mercado delas atinge frequentemente extensões até pontos remotos do mundo. Duas linhas de abordagem analítica ajudam a clarear este estado aparentemente paradoxal de negócios. Em primeiro lugar, produtores nos setores cognitivo culturais da economia possuem uma propensão definida para se aglomerarem em espaço geográfico por razão das economias externas de escala e de escopo (ou efeitos de retornos crescentes) que fluem de aspectos seletivos de sua operação em conjunto em localidades particulares. O papel de redes inter-firmas flexíveis, de mercados de trabalho local, e de processos localizados de aprendizagem é extremamente crítico neste caso. (COOKE e MORGAN, 1988; SCOTT, 2000; STORPER, 1997). Grupos de produtores com fortes interdependências em relação a estas variáveis possuem poderosa indução para gravitar na direção do seu centro de gravidade comum. Deste modo reduzem os custos espaço-tempo de suas relações transnacionais negociadas, ou não, e engrossam o estoque total de economias externas conjuntamente geradas. Embora seja verdade que baixos custos de transações (e mesmo em queda) tornam possível, para alguns tipos de firmas, dispensarem as vantagens de aglomeração e descentralizar para localizações de baixo custo, o mesmo fenômeno permite também que muitos outros tipos de produtores de gozar do melhor de ambos os mundos. (Ficar ancorados dentro de um cluster específico, continuar a se apropriar de vantagens competitivas localizadas, e, simultaneamente contestando mercados globais). Com a ampliação do nível de produtores, em qualquer cluster, o crescimento econômico local acelera, levando ao aprofundamento de efeitos de retorno localizados e crescentes, e intensificando a aglomeração. Os sinais desse desenvolvimento dinâmico aparecem palpáveis nas atuais grandes áreas metropolitanas mundiais. Em ambas, na incidência de crescimento rápido de setores cognitivo culturais, e na expressão freqüente deste crescimento na formação de distritos industriais intra-urbanos devotados a facetas especializadas da produção cognitiva cultural (ARAI et allii, 2004; CURRID, 2006; PRATT, 1996; RANTISI, 2004; SCHOALES, 2006). Exemplos clássicos destes desenvolvimentos é a produção de alta tecnologia e software na are da Baía de São Francisco, a indústria do entretenimento em Hollywood e no seu entorno, os centros de negócios em Nova York e Londres, e os mundos da moda de Paris e Milão. 
Junto com o crescimento espraiado de sistemas de produção cognitivo culturais na cidade moderna, vieram numerosas transformações paralelas de espaço intra-urbano, incluídos aumentos significativos na forma e função de diversas partes privilegiadas do tecido urbano. Entre o mais sintomático aspecto desta tendência se encontra o processo geral de elevação social e econômica das áreas antigas de centro da cidade e de seus entorno. Tal processo é largamente referido na literatura como gentrificação, (SMITH, 2002; ZUKIN, 1982), embora o conceito, originariamente se referisse a incursões de domicílios de classe média em vizinhanças decadentes do interior da cidade. O que está em causa atualmente, neste sentido, é não menos do que uma radical transformação de enormes porções do espaço urbano, por uma lógica quadripla de desenvolvimento econômico cognitivo cultural, transformação social, mudanças de atendimento funcional e a re-imaginação do ambiente por meio de novos simbolismos dramáticos.

Manifestação crescente deste processo são a reciclagem e elevação de velhas zonas industriais e comerciais da cidade, para prover novos espaços hábeis a acomodar atividades de produção e consumo de alto nível. Fachadas da baía em Baltimore, das docas de Londres e o desenvolvimento do Oeste de Zurique são exemplos notáveis deste fenômeno. Iniciativas do gênero podem ser encontradas na Grã Bretanha, no Quarteirão Norte de Manchester, e no Quarteirão de Indústrias Culturais de Sheffield, que aspiram desenvolverem-se como hubs dinâmicos de pequenas empresas criativas, tais como, gravadoras de música, laboratórios de mídia, eletrônica, estúdios de design da moda e similares. Em Los Angeles, um novo Distrito de Moda, logo ao sul do distrito central de negócios, foi criado recentemente, que era originariamente um cluster dissolvente de fábricas encardidas de roupa. Este desenvolvimento, com os seus prédios renovados e com cenários de rua coloridos, expressam o status crescente da indústria de vestuário de Los Angeles como um centro global de designers de moda. Ajudam sustentar as novas ambições achadas por muitos produtores locais, no sentido de competirem em mercados finais elevados (SCOTT, 2000). Em iniciativas similares, autoridades locais, em cidades ao redor do mundo, se encontram engajados em projetos que envolvem a conversão de dispositivos abandonados, para servirem a uma diversidade de proposições culturais, como o caso da fábrica de gás ocidental de Amseterdam, ou de trechos da Região do Rhur, na Alemanha, onde ocorrem de forma agressiva, esforços de reconstrução de paisagens industriais decadentes. 
Um caso relacionado, e crescentemente espetacular na reciclagem do espaço urbano, consiste na construção de uma série de peças arquitetônicas de larga escala, que passam a funcionar com expressão de ícones de aspirações locais econômicas e culturais, na era do capitalismo cognitivo cultural. Os grandes projetos postos de pé em Paris, pelo presidente François Mitterrand, nos anos 80, representa um pioneirismo e certamente um exemplo dos mais determinados desta espécie de ambição. Fez muito para acrescentar à já reputação celebrada de Paris, o reconhecimento de ser um ponto de referência cultural global. Outros casos ilustrativos de re-imaginação de projetos urbanos, no objetivo de status econômico cultural se encontram no Museu Guggenheim de Bilbao, na Frente Portuária de Toronto, e nas torres Petronas de Kuala Lampur. Projetos que registram a presença do estágio global, enquanto geram prestígio e caixa que se derramam sobre comunidades mais largas nas quais se encontram inseridos.

Elites urbanas, em todas as partes do mundo, estão crescentemente comprometidas na busca de projetos como os citados, em tentativas de asseverar a visibilidade de suas cidades, como focos de interesse cultural e de promessa econômica na nova ordem global.

Enquanto estas mudanças ocorriam, amplas porções de vizinhanças de baixa renda em áreas centrais das cidades foram sujeitas à apropriação e re-colonização por setores afluentes da população. Este processo se expressa na renovação de velhas propriedades residenciais de classe trabalhadora e de áreas degradadas abandonadas. Se expressa, também, a venda de conjuntos de terrenos aterrados, para acomodarem novos blocos de condomínios caros. Uma gentrificação deste tipo vinha ocorrendo nas cidades da América por décadas, porém se acelerou grandemente em anos recentes, como resultado de mudanças nas condições estruturais do ambiente urbano, e de mudanças de prioridades nas preferências habitacionais. Particularmente, como os empregos na manufatura tradicional e nas vendas a grosso declinaram nas áreas urbanas internas, muitos da população da antiga classe trabalhadora, das comunidades adjacentes, migrou para outras partes da cidade. Paralelamente, oportunidades de emprego para trabalhadores cognitivo culturais dentro e em torno do distrito central de negócios cresceram em cogumelo nos últimos anos, e muitos destes trabalhadores estão assumindo residência em vizinhanças próximas, para reduzir tempos de transporte e ganhar acesso ao lazer das compras e das facilidades culturais na cidade. É muito comum que o primeiro sinal, de que uma seção dilapidada da parte interna da cidade Geo UERJ - Ano 12, nº. 21, v. 2, p. xx-xx $2^{\circ}$ semestre de 2010. www.geoueri.ueri.br/ojs ISSN 1981-9021 
está fadada a entrar em tal sorte de transição, seja a irrupção de grupos de artistas e de boêmios na área, e o florescimento de estúdios, cafés, clubes, etc. (ZUKIN. 1982). Realmente, alguns analistas deram a estes grupos, assim como a gays, um status especial, enquanto arautos e moléculas encaminhadoras da síndrome de “cidade criativa”. (FLORIDA, 2004; LLOYD, 2002; LLOYD e CLARK, 2001) A presença evidente destes grupos na paisagem urbana é dita como sintomática de um estado de abertura e tolerância na sociedade local, qualidades que, por sua, são pensadas como essenciais para o florescimento de um ambiente criativo Neste sentido, a presença ou ausência destes grupos na cidade é tomada por certos comentaristas como uma espécie de teste crucial da propensão para a “criatividade” em geral.

Portanto, há numerosos sinais de importantes tendências nas funções e formas das cidades, enquanto as fundações cognitivas culturais do capitalismo moderno se aprofundaram e se alargaram. Estas tendências são detectadas nos padrões econômicos, nas organizações sociais e na estrutura física de muitas cidades diferentes. Áreas especializadas da cidade dedicadas ao entretenimento, recreação, edificação e compras passaram por muita elaboração e embelezamento, componentes, componentes insistentes da vida urbana contemporânea, Algo parecido como o que ocorre com indivíduos de alto nível cognitivo cultural, em mencionar os bem providos de dinheiro (ZUKIN, 1995). Neste sentido, uma nova espécie de equilíbrio e integração parece estar emergindo, ao menos, nas seções privilegiadas das cidades modernas, entre a economia e a sociedade, entre a produção e o consumo, entre o trabalho e o lazer e entre o comércio e a cultura. Entretanto uma nuvem negra paira sobre este quadro gratificante. Ela é composta pela redução subjacente de funções industriais e de serviços de baixos salários, que, invariavelmente deveriam ser encontradas nas grandes áreas metropolitanas, onde funções econômicas cognitivas culturais se encontram desenvolvidas em grau maior. É composta, também, frequentemente, por problemas quanto a áreas residenciais, fontes para manter o trabalho necessário para a manutenção destas funções.

O encobrimento aprofundado por estas condições de desigualdade social e econômica, quase certamente coloca algemas sobre o potencial da cidade para desempenho criativo e sobre a sua capacidade de promover, consistentemente, níveis elevados de aprendizagem social, inovação econômica e convivência humana, Segmentos amplos da Geo UERJ - Ano 12, n'. 21, v. 2, p. Xx-Xx $2^{\circ}$ semestre de 2010. www.geoueri.ueri.br/ojs ISSN 1981-9021 
população urbana enfrentam sérios impedimentos para participarem como cidadãos plenos na vida e trabalho diário. Uma circunstância geradora de altos custos para os indivíduos diretamente concernentes e - através das múltiplas externalidades negativas resultantes desta situação - para a sociedade urbana como um todo. Os problemas de uma cidadania dividida e desigual ainda compreendem o fato de muitos dos grupos desprivilegiados das grandes áreas metropolitanas consistem atualmente de imigrantes de países pobres, imersos na órbita da economia urbana pelas oportunidades de empregos de baixo salário que proliferam nestas áreas. Em muitos casos, estes imigrantes formam vizinhanças poli étnicas e polilinguisticas no interior do espaço social da metrópole, deste modo exacerbando a separação e o isolamento social, que constantemente trabalha contra a formação de um sentido mais largo de comunidade. A retirada incessante de serviços públicos que está ocorrendo no contexto do clima neoliberal, prevalecente em muitos dos países capitalistas mais avançados atua para intensificar o individualismo possessivo. Este é uma característica forte da vida urbana moderna, a expensas de valores comunitários. Igualmente, enquanto a globalização segue o seu curso, os ecos geográficos estendidos destes mesmos predicados se tornam ainda mais altos. De um lado, novas expressões de solidariedade formal orgânica via a divisão de trabalho. Assumem forma em escala global, quando crescentes volumes de trabalho de baixo salário são transferidos dos países mais avançados economicamente, para diversas localizações do mundo em desenvolvimento. Por outro lado, esta tendência prossegue sem as inconveniências concomitantes de propineqüidade para mais estratos sociais privilegiados do mundo desenvolvido. Deste modo a responsabilidade ou contabilidade por indivíduos dos estratos de cima em relação a indivíduos dos estratos de baixo se torna mais diminuída.

Os trabalhadores cognitivos culturais e a constituição da vida urbana.

Nas últimas décadas, muitos cientistas sociais se dedicaram a descrever a estratificação mutante da sociedade capitalista e a tipificar as tendências ocorridas na estrutura social, desde o auge da divisão clássica colarinhos brancos/colarinhos azul que prevaleceu nas cidades da América, durante grande parte do século 20. Numa colocação pioneira, Bell (1973) aludiu ao advento do que chamou de sociedade pós-industrial, e sugeriu que as velhas divisões do capitalismo estavam sendo realmente transcendidas. Por uma nova direção de completudes pessoais e auto-realizações numa economia orientada para Geo UERJ - Ano 12, no. 21, v. 2, p. xx-xx $2^{\circ}$ semestre de 2010. www.geoueri.ueri.br/ojs ISSN 1981-9021 
serviços. Gouldner (1979) nos oferece a idéia de uma "nova classe” constituída de indivíduos que internalizaram uma ideologia de racionalidade crítica; para estes indivíduos, argumentos racionalizados assumem precedência em relação à autoridade hierárquica, como base de credo e ação. O tecnocrata moderno é a figura emblemática da nova classe. Reich (1992), por sua vez, se refere a "trabalhadores simbólicos" que, segundo ele, se constituem na elite de uma de uma sociedade informacional emergente. Sklair (2000) alarga o quadro com o conceito de "classe capitalista transnacional” composta de gerentes, profissionais e técnico engajados em formas de trabalho que expressam e promovem o projeto histórico da globalização.

Mais recentemente, Florida (2002), fez avançar o argumento de que uma nova “classe criativa” compreendendo todos estes trabalhadores engajados numa forma ou noutra de trabalho intensivo pensante veio para se na sociedade Americana.

Cada uma destas colocações que fala algo da organização mutante da sociedade no capitalismo contemporâneo, possui,inquestionavelmente, algo de interessante e de significância para conferir, embora nenhuma seja totalmente satisfatória. O termo “classe” é talvez indevidamente forte para ser usado para alguns destes grupamentos sociais um tanto nebuloso, especialmente, tendo em vista a sua conotação mais ortodoxa, de dois estratos opostos cujos interesses se chocam, como conseqüência de suas relações estruturais em relação aos meios de produção e de seus reclamos opostos sobre o excedente econômico, Adicionalmente, como argumentado por Markusen (2006), a proposição de Florida de uma classe criativa, é algo de incoerente como conceito, uma vez que reúne uma variedade muito disparatada de indivíduos - desde os situados como executivos de companhias, a programadores de software, de financistas internacionais, a artistas - em limites mais para elásticos. Esta diversidade tão pouco se ajusta à idéia weberiana, mais diluída, de classe, uma vez que se baseia em ocupações e oportunidades de vida. Ainda mais problemático é o modo de Florida armar os indivíduos que compõem o segmento mais privilegiado da sociedade capitalista, como se possuíssem uma espécie de capacidade ontológica de “criatividade”. Trata-se de uma caracterização que carreia consigo um sobrepeso de implicações hilariantes, mas, isto seria ainda pouco em termos do seu significado concreto. Na realidade, as formas distintas de capital humano que estes indivíduos possuem - especificamente as tarefas cognitivas culturais a que eles são chamados a desempenhar - são, em sua maioria, cunhados por entalhos sociais preenchidos com substância muito específica, no quando 
do capitalismo contemporâneo. Estas tarefas se encontram focalizadas em atividades que incluem gestão técnica neoliberal, processos orientados para a inovação e design de produtos, nas provisões personalizadas de serviços, na naturalização de aptitudes e crenças socialmente úteis (por exemplo, em instituições educacionais e na mídia).. Contam-se ainda, a comercialização de experiências, encontros culturais, e procura de lazer. Menção especial deve ser dada, neste contexto, à recente enorme expansão, em geral, de produtos industriais culturais e à concomitante emergência de um segmento importante força de trabalho cognitiva cultural dedicada a conceber e fabricar outputs cuja função é entreter, instruir, embelezar e reforçar identidade (BOURDIEU, 2979, HESMONDALGH, 2002, POWER e SCOTT, 2004). Este é um mundo, como mostrado por Lash e Urry (1994), no qual cultura é produzida na forma de commodity, enquanto que a própria produção de commodities se torna mais revestida de significados estéticos e semióticos. A continua convergência do econômico e do cultural no capitalismo contemporâneo levou alguns teóricos pós-modernos a reclamar - sem dúvida corretamente - de que a esfera da cultura hoje em dia se encontra sujeita de forma endêmica a uma condição do empalidecer da intensidade simbólica e de aumento da condição do efêmero (JAMESON, 1992).

Diversas intimações provenientes da lógica e do sentido das novas forças sociais e dos alinhamentos que estão crescendo à frente da sociedade capitalista, se tornaram um tema comum de relatos jornalísticos sobre realidades econômicas e urbanas. Entre as mais proeminentes destas efusões sobre a nova economia, se encontra uma corrente de teorias de gestão e de assessoria direcionada para as qualidades pessoais e afetivas requerida para colocar ordem e dinamismo nos locais de trabalho. cognitivo cultural. O discurso normativo de analistas e consultores de gestão é atualmente menos preocupado, do que já foi, com assuntos terrenos como eficiência e controle, e muito mais focalizado em métodos cultivadores recursos humanos, incluídos liderança, empatia, auto-motivação, adaptação, inventividade, preenchimento de recursos e consciência ética, num ambiente de movimentos rápidos e de negócios em alto risco. ( BOLTANSKI e CHIAPELLO. 1999, THRIFT, 2005). Incontestavelmente, há muito neste discurso que ajuda gerentes e trabalhadores na procura de obtenção de uma dada estratégia para o problema diário que enfrentam no novo ambiente econômico cognitivo e cultural. Embora, seja, distintamente, menos útil como guia para a formulação de um pensamento crítico, ou como uma base para a construção de imaginações politicamente Geo UERJ - Ano 12, no. 21, v. 2, p. xx-xx $2^{\circ}$ semestre de 2010. www.geoueri.ueri.br/ojs ISSN 1981-9021 
plausíveis a respeito de possibilidades alternativas. Diversos ecos deste discurso ressoam no atual credo da moda da cidade criativa. Eles trazem a mensagem batida a respeito da transformação das áreas urbanas por meio de programas designados a equalizar os membros da "classe criativa” que, então, presumivelmente, expressarão seus talentos e energias de modo a multiplicar benefícios econômicos e culturais locais (FLORIDA, 2004). Uma vez mais, podemos encontrar elementos nas análises que merecem nossa atenção, mesmo que cruamente eles sobre simplificam os desafios políticos que devem ser tratados em qualquer programa de desenvolvimento econômico (quanto mais, quando se trata de erigir oportunidades de emprego). E mesmo que obscureçam as funções e significados específicos, históricos do trabalho intelectual e simbólico no capitalismo contemporâneo. Ao mesmo tempo, seria talvez válido refletir que o mesmo credo tende a projetar uma fé exageradamente otimista nos impactos benignos sociais e políticos da chamada classe criativa, pelo menos, pela razão de seu impregnado silêncio a respeito do aprofundamento da divisão social nas cidades de capitalismo avançado atual. Também, pelo seu sinal de falha em colocar a questão qualquer um dos aspectos mais regressivos da cena cultural contemporânea, trabalhado por esta fração da força de trabalho. Isto dito, no trabalho mais recente de Florida (2005), ele inicia retificando algumas destas lacunas, reconhecendo as ligações entre a nova economia e a desigualdade econômica.

Os aspectos menos cativantes da economia cognitiva cultural ficam ampliados pelos problemas adicionais do crescimento rápido de níveis de instabilidade social e do risco, de modo que todos os estratos - mesmo a elite urbana - estão sujeitos a uma intensificação geral da vida se tornar mais precária (BECK, 2000). Membros individuais da força de trabalho injetam considerável energia e tempo navegando por caminhos entre recifes e baixios da existência prática social. Seja através de trabalho em rede muito auto consciente da camada superior de trabalhadores (BAT T et allii, 2001; NEFF et allii, 2005. URSELL, 2000), ou via diversas ligações étnicas ou de famílias estendidas, no setor da camada inferior (SANDERS et allii, 2002; WALDINGER, 2001). Muitos tipos de trabalhadores cognitivos culturais - especialmente os que se encontram nos estágios iniciais de suas carreiras - são inveterados participantes de grupos sociais relacionados ao trabalho e se encontram prontos a despender grandes partes do tempo fora de suas horas de trabalho normal, para a construção de relações 
com trabalhadores aliados, no propósito de manter seu posicionamento no mercado (SCOTT. 2000).

Nestas condições, a interação humana é apta para assumir tonalidades utilitárias discerníveis. Assim, num estudo sobre trabalhadores da indústria de TV, Ursell (2000) mostrou como uma "economia de favores” apareceu, na qual informações a respeito de oportunidades de emprego e assuntos de trabalho relacionados são trocadas numa base de um quid pro quo, através de redes extensas de contatos sociais. Ao mesmo tempo, o caleidoscópio das tendências de oportunidades ou de recuos, que tanto caracteriza a atual economia cognitiva cultural, é crescentemente refletido em carreiras que se abrem segundo muitos tipos de empregadores e por muitos lugares, e frequentemente especialmente para a camada superior de trabalhadores - em muitos países diversos. Deste modo, a conexão tradicional entre parentesco e comunidade se sujeita a recuo, enquanto se estabelece um novo etos de engajamento inter-pessoal, sem compromisso durável, como condição normal de existência urbana. A mesma instabilidade e insegurança prove forte incentivo aos membros da camada superior $d$ força de trabalho, para se se engajarem em persistente autopromoção e auto publicidade. Um incentivo que, sem dúvida, aumenta na medida em que eles se expressam através de um porte fólio de experiências e qualificações que os marcam como os donos de um pacote único de atributos e talentos. Em testemunhos das observações acima, Sennett (1998) apontou para uma corrosão aparente de formas tradicionais de afetividade e de crédito, em ambos, no lugar de trabalho e na sociedade. Já Putnam (2000) escreveu de forma mais geral sobre o enfraquecimento dos laços de comunidade na América.

É se tentado a atribuir, pelo menos algo do narcisismo, pensado por Lasch (1978), como estando em alta no psiquismo da América, a forças sociais e a predicados de tipos acima mencionados. Um modo menos ambicioso de seguir muito o mesmo caminho, é o de apelar para a evidente acumulação na expansão da esfera do privado e do pessoal, e de uma contração correspondente da esfera pública nas cidades da América. Bem ao lado da condição de penúria pública e de amplo declínio do sentido de comunidade, que vem de ser invocado, é possível ver os efeitos imediatos deste estado de coisas, na fragmentação intensa do espaço social da metrópole contemporânea. A grande diversidade social que é tão frequentemente celebrada, como uma das principais condições para a criação atual de um ambiente urbano criativo, na verdade se inscreve numa paisagem da metrópole com padrões de separação e desligamentos, acentuados 
pela marginalização aguda de uma permanente expansão de população imigrante da cidade. Para muitos imigrantes, esta situação se manifesta por uma pobreza relativa e absoluta, além de perdas de franquias políticas. O fato de que muito destes deslizes das cidades da América, no começo do século 21, tenham encurtado os direitos e restringido canais de expressão democrática de suas aspirações políticas, significa, não apenas, que elas negaram a incorporação plena na sociedade urbana, mas, também, que elas limitaram incentivos capazes de estabelecer compromissos duráveis de longo prazo para a comunidade. O resultado líquido é mais deterioração da capacidade do sistema urbano de soltar e mobilizar o potencial criativo de cidadania. Talvez, um dos sintomas mais expressivos do caráter de inhospitabilidade da cidade de extremos sociais, como a que se acha na América contemporânea, é a proliferação de vizinhanças entre cercas e a transformação de importantes seções do espaço urbano em zonas de exclusão explícita (BLAKELY e SNYDER, 1999). Tal fenômeno representa um golpe direto no uso democrático do espaço urbano e uma violação verdadeira e simbólica no princípio da cidadania compartilhada,

Para além da cidade criativa

Enquanto que as formas de produção e trabalho cognitivas culturais penetram mais profundamente a sociedade capitalista contemporânea, uma enorme variedade de conjuntos de respostas urbanas foi colocada em movimento. Uma série de espaços intrametropolitanos privilegiados, dando suporte a atividades de trabalho, residência e laser da nova elite cognitiva cultural, é,agora, um ingrediente importante de muitas cidades do mundo Por outro lado, e considerando que um grande número de empregos de baixa renda e baixa qualificação se constituem num elemento maior da economia cognitiva cultural, uma crescente subclasse é também um dos aspetos das mesmas cidades. Estas tendências se encontram incrustadas numa dinâmica que se alarga de integração econômica cultural em escala global, conduzindo a formas complexas de especialização e de interdependência pela paisagem global.

Alguns dos aspectos mais positivos deste quadro têm sido altamente iluminados por uma série de comentários normativos focalizados nos potenciais criativos das cidades contemporâneas Compreende-se que tomadores de decisões políticas e planejadores em diversas partes do mundo tenham aberto muito entusiasmo em relação a estes Geo UERJ - Ano 12, no. 21, v. 2, p. xx-xx $2^{\circ}$ semestre de 2010. www.geoueri.ueri.br/ojs ISSN 1981-9021 
comentários. Em numeroso casos, embarcaram de verdade em tentativas de fazer suas cidades apelarem aos talentos altamente qualificados de indivíduos pensados, na versão mais proeminente da história, como o movente primaz da cidade criativa. A déia da cidade criativa é ainda mais irresistível aos olhos dos tomadores de políticos tomadores de decisões dada a sua promessa de empregos de salários altos em setores da atividade econômica que não se chocam com questões ambientais, e assim, elevar o fabrico do urbano. Num número de casos, as tentativas práticas de seguir pela idéia foram complementadas por esforços de montar apresentações peças arquitetônicas desenhadas cm maestria, para atrair a atenção de visitantes potenciais e de investidores, e para estabelecer dramatizados pontos de referência, na corrida global por influência econômica e cultural. Florida $(2002,2004)$ tem sido um dos mais instigadores de tal agenda normativa, mas, as suas idéias encontram suporte implícito e explícito em outros trabalhos, incluído o conceito de "cidade do consumo" formulado por Glaeser et allii (2001) e a visão da cidade como a "máquina do entretenimento", proposta por Lloyd e Clark (2001). A estratégia sugerida por Florida para a construção da cidade criativa pode ser esquematizada - apenas, com uma ponta de obstinado cepticismo - em termos de três pinceladas. Primeiro, as autoridades municipais são aconselhadas a encorajar desenvolvimento de amenidades reclamadas como sendo de valor pela classe criativa. Ciclovias e restaurantes da moda figuram de forma proeminente nas sugestões oferecidas (e análises de regressão indicam que invernos mornos também ajudam no caso); cinemas, galerias de arte seriam aparentemente de conseqüência bem menor. Segundo, Florida propõe que uma vez que pacotes de amenidades forma instaladas numa dada cidade, membros da classe criativa serão induzidos de aí irem morar, especialmente se uma atmosfera de tolerância e abertura também prevalecer. Isto ocorrendo, diversas energias criativas serão, presumivelmente, soltas. Terceiro, consequentemente, a expectativa é de uma aceleração do dinamismo da economia local, junto com a elevação da escala do ambiente construído e com o aumento do prestígio geral de atratividade da cidade como um todo.

Eu tenho criticado esta abordagem em outros locais (SCOTT, 2004, 2006), e reafirmo que cidades estão sujeitas a trajetórias de crescimento dependentes de caminhos nos quais ambos, o suprimento e a demanda por força de trabalho se movem segundo padrões de causação mútua cumulativa. O motor primário deste processo não é a migração para o interior e unilateral de um tipo particular de trabalhadores, mas o Geo UERJ - Ano 12, no. 21, v. 2, p. xx-xx $2^{\circ}$ semestre de 2010. www.geoueri.ueri.br/ojs ISSN 1981-9021 
aparato complexo do sistema de produção urbana, (isto é, a rede de atividades industriais e de serviços inter-relacionadas, gerando desenvolvimento econômico locacionalmente polarizado). Este tipo de motor desenvolvimentista esteve trabalhando obviamente nos primeiros períodos do capitalismo e é ainda reconhecido como a força motiva maior da urbanização no capitalismo cognitivo cultural atual. Considere-se o caso das cidades dos centros industriais na Inglaterra do século 19. Não foi a acumulação prévia de densa força de trabalho que explica a formação destes centros, mesmo que a presença de uma população da classe trabalhadora seja essencial para o funcionamento de um centro fabril. Do mesmo modo, o crescimento do Silicon Vale na segunda metade do século 20 não pode ser atribuído invocando-se a existência prévia de alguma classe criativa indiferenciada na área loca, assim como seria certamente absurdo reivindicar que a força dirigente da expansão de longo prazo do Vale seja devida a incursões contínuas de membros desta classe a procura de valores de amenidades. Pelo contrário, a acumulação histórica, no Vale do Silício, de uma força de trabalho compreendendo técnicos especializadas de semicondutores, cientistas de computação, software e engenheiros só é compreensível quando se coloca esta tendência numa rede envolvente de atividades de produção especializada e de oportunidades de emprego ligados a cada mercado final em alargamento para semicondutores, computadores e software. Sim, o suprimento de trabalho é um momento crucial na cadeia da intermediação temporal, através da qual centros de produção e trabalho cognitivo cultural evoluem, mas continua sendo um momento subordinado, no sentido de que, o poder gerador de desenvolvimento econômico local reside, proeminentemente, no caminho da dependência lógica de produção, aglomeração e especialização regional. Pela mesma moeda, a dissipação deste poder é u caminho virtualmente inevitável de para ruína, mesmo que grande número de trabalhadores de alto nível de capital humano continue a morar na área local. Tomadores de decisões políticas negligenciam estes aspectos do problema a seu risco.

Além destes sopros analíticos subjacentes a muito do trabalho recente sobre a cidade criativa, uma estranha reticência pode ser detectada em muitos dos reclamos avançados em relação às possibilidades do reviver da vida social e do ambiente físico de cidades, batendo nos poderes expansionistas da economia cognitiva cultural. Enquanto formas de produção e de trabalho oferecem novas e dinâmicas possibilidades de regeneração urbana, elas apontam que existe um lado escuro na dialética do desenvolvimento das cidades contemporâneas e que o aprofundamento de uma tendência neoliberal exacerba 
o problema. Esta premissa levanta questões levanta questões a respeito da reconstrução da sociedade urbana que vão bem além de simples pleitos por aberturas, tolerância e diversidade; estes são excelentes objetivos, porém, não garantem a transcendência do isolamento social, da fragmentação e da desigualdade, Ao contrário, mesmo que estas qualidades estejam presentes universalmente, a lógica estruturalmente engrenada da ordem econômica e social contemporânea continuaria fazer crescer a iniqüidade e injustiças conspícuas nas grandes cidades. Em contraste com a agenda política neoliberal que atualmente se balança nos Estados Unidos, e que é endemicamente associada a elevados níveis de pobreza urbana e de privações, somente algum tipo de programa consciente de social democracia, com forte foco re-distribuitivo, emprego decente para todos e o re-engajamento da cidadania no pensamento político, parece apropriado a endereçar reforma social.

Além da implantação de princípios elementares de equidade social, justiça e democracia participativa, um desafio adicional assoma, Como as cidades tendem para modos de atividade econômica cognitiva cultural, a procura por formas significantes de solidariedade, sociabilidade e ajuda mútua no trabalho e na vida diária se torna crescentemente urgente. - não apenas porque estes atributos são importantes em seu direito próprio - mas, também, porque alargam a esfera da criatividade, aprendizagem, inovação, experimentação social e expressão cultural. Ele são essenciais para um contínuo florescimento econômico e cultural das cidades contemporâneas, É bem possível que alguns dos objetivos desta procura possam ser realizáveis se, como Judôs e Teixeira (2002) a expectativa de uma nova maioria progressista começa a tomar forma no que chamam de cidades "pós-industriais”.

Finalmente, um imperativo ainda maior é trazido para frente, enquanto a economia cognitiva cultural continua seu acento e enquanto o conteúdo afetivo simbólico dos produtos finais se torna ainda mais presente. O consumo destes produtos possui potentes impactos diretos e indiretos na consciência humana e na orientação ideológica e este processo, pela mesma moeda, gera externalidades maciças para todos. Estas externalidades dão margem a dilemas complexos, uma vez que reaparecem em diversas roupagens sociais e políticas com profundas implicações para o modo de ser social. E precisamente porque eles são externalidades, elas nunca podem ser adequadamente processadas apenas via racionalidade de mercado. Um persistente debate público e a Geo UERJ - Ano 12, no. 21, v. 2, p. xx-xx $2^{\circ}$ semestre de 2010. www.geoueri.ueri.br/ojs ISSN 1981-9021 
mútua educação a respeito dos significados pessoais e das conseqüências políticas do lado do consumo da economia cognitiva cultural - e a respeito das possibilidades de maior participação criticamente informada - é mais um pré-requisito de uma ordem progressista e democrática no capitalismo contemporâneo.

* Traduzido e resumos por Pedro Geiger

Referências

ARAI, Y, NAKAMURA, H e SAUO, H, 2004, Multimídia and Internet Business Clusters in Central Tokyo, Urban Geography, 25: 483-500.

AUTOR, D H, KATZ, L F, e KEARNEY, 2006, The Polarization of the US Labor Market, American Economic Review 96:189-94.

AUTOR, D H, LEVY, F, e MOURNANE, R J, 2003, The Skill Content of Recent Technological Change: An Empirical Exploration, Quarterly Journal of Economics 118:1379-1333.

BATT, R, CHRISTPHERSON, S, RIGHTOR, N, e VAN JAARSVELD, 2001, Net Working: work Patterns and Workforce Policies, for the New Media Industry, Washington, DC, Economic Policy Institute.

BECK, U, 2000, The Brave New World of Work, Polity Press.

BELL, D 1973, The Coming of Post-Industrial Society; a Venture in Social Forecasting, Basic Books. .

BLAKELY, E J e SNYDER, M G, 1999, Fortress America: Gated Communities in the United States, Brookings Institution Press.

BOLTANSKI, L, e CHIAPELLO, E, 1999, Le Nouvel Esprit du Capitalisme, Gallimard.

BOURDIEU, P, 1979, La Distinction : Critique Sociale du Jugement, Le Sens commun. BOYER, R, 1986, La Théorie de la Régulation : Une Analyse Critique, Algalma.

COOKE, P e MORGAN, K, 1998, The Associational Economy: Firms, Regions, and Innovation, Oxford University Press.

CURRID, E, 2006, New York as a Global Creative Hub: A Competitive Analysis of Four Theories on World Cities, Economic Development Quarterly 20: 330-350

FLORIDA, R, 2002, The Rise of the Creative Class, Basic Books 2004, Cities and the Creative Class, Routledge. 
2005. The Fight of the Creative Class: The New Global Competition for Talent, Harper Business.

GLAESER, E L, KOLKO, J, e SAIZ, A, 2001, Consumer City, Journal of Economic Geography, 1:27-50.

GOULDNER, A, 1979, The Future of Intellectuals and the Rise of the New Class, Seabury.

HALL, P, 1998, Cities in Civilization, Pantheon.

HESMONDHALGH, D, 2002, The Cultural Industries, Sage.

JAMESON. E, 1992, Postmodernism, or, the Cultural Logic of Late Capitalism, Duke University Press.

JESSOP, B, 2004, Critical Semiotic Analysis and Cultural Political Economy, Critical Discourse Studies, 1:1-16

JUDIS, J B, e TEIXEIRA, R, 2002, The Emerging Democratic Majority, Scribner.

LANDRY, C, 2000, The Creative City: A Toolkit for Urban Innovators, Earthscan.

LASCH, C, 1978, The Culture of Narcissism: American Lfe in an Age of Diminishing Expectations, Norton.

LASH, S, e URRY, J, 1994, Economies of Signs and Space, Sage.

LEVY, F, e MURNANE, R J, 2004, The New Division of Labor: How Computers are Creating the Next Job Market, Russell Sage Foundation.

LLOYD, R, 2002, Neo-Bohemia: Art and Neighborhood Development in Chicago, Journal of Urban Affairs 24:517-32.

LLOYD, R, and CLARK, TN, 2001, The City as an Entertainment Machine, in Critical Perspectives on Urban Redevelopment, K F Gotham, editor, : 357-78 Elsevier.

MARKUSEN, A, 2006, Urban development and the Politics of a Creative Class: Evidence from a Study of Artists, Environment and Planning A 10:1921-40.

MCROBBIE, A 2004, Making a Living in London 's Small-Scale Creative Sector, Cultural Industries and the Production of Culture, D Power e A J Scott editores::13043, Routledge

MORRIS, M e WESTERN, B, 1999, Inequality in Earnings at the Close of the Twentieth Century, Annual Review of Sociology 25:623-57.

NEFF, G, WISSINGER, E, e ZUKIN, S, 2005, Entrepreneurial Labor among Cultural Producers: Cool Jobs in Hot Industries, Social Semiotics 15: 307-34

POWER, D e SCOTT, A J, Editores, 2004, Cultural Industries and the Production of Culture, Routledge. 
PRATT, A C, 1997, The cultural Industries Production System: a Case Study of Employment Change in Britain, 1984-91, Environment and Planning A 29:1953-74.

PUTNAM, R, 2000,: The Bowling Alone Collapse and Revival of American Community, Simon \& Schuster.

RANTISI, N, 2004, The Designer in the City and the City in the Designer, Cultural Industries and the Production of Culture, D Power e A J Scott editores: 91-109, Routledge.

REICH, R, 1992, The Work of Nations, Vintage.

SANDERS, J, NEE, V, e SERNAU, S, 2002, Asian Immigrants 'Reliance on Social Ties in a Multiethnic Labor Market, Social Forces 81: 281-314

SASSEN, S, 1994, Cities in a World Economy, Pine Forge Press.

SCHOALES, J, 2006, Alpha Clusters: Creative Innovation in Local Economies, Economic Development Quarterly, 20: 162-77.

SCUTT, AJ, 2000, The Cultural Economy of Cities: Essays on the Geography of ImageProducing Industries, Sage , 2002, Competitive Dynamics of Southern California 's Clothing Industry: the widening Global Connection and its Local Ramifications, Urban Studies 39: 12871306.

2004, Cultural Products Industries and Urban Economic Development: Prospects for Growth and Market Contestation in Global Context, Urban Affairs Review, 39: 461-90.

2006, Creative Cities: Conceptual Issues and Policy Problems, Journal of Urban Affairs 28:1-17.

SENNETT, R, 1998, The Corrosion of Character: the Personal Consequences of Work in the New Capitalism, W.W, Norton.

SKLAIR, L, 2000, The Transnational Capitalist Class, Blackwell.

SMITH, N, 2002, New Globalism, New Urbanism: Gentrification as Global Urban Strategy, Antipode, 34: 427-50.

STORPER, M, 1997, The Regional World: Territorial Development in a Global Economy, Guilford Press.

THRIFT, N, 2005, Knowing Capitalism, Sage.

URSELL, G, 2000, Television Production: Issues of Exploitation, Commodification and Subjectivity in UK Television Markets, Media, Culture and Society, 22: 805-25. 
WALDINGER.R, 2001, The Immigration Niche in Global City-Regions: Concept, Patterns, Controversy, Global-City Regions: Trends, Theory, Policy, A J Scott editor, :299-322, Oxford University Press.

YUN, M S, 2006, Earnings Inequality in USA, 1069-99: Comparing Inequality Using Earnings Equations, Review of Income and Wealth 1:127-44.

ZUKIN, S, 1982, Loft Living: Culture and Capital in Urban Change, John Hopkins University Press.

, 1995, The Cultures of Cities, Blackwell.

Enviado para publicação em novembro de 2010.

Aceito para publicação em dezembro de 2010. 